\title{
Heated Humidification Improves Clinical Outcomes, Compared to a Heat and Moisture Exchanger in Children With Tracheostomies
}

\author{
David G McNamara MBChB FRACP PhD, M Innes Asher MBChB FRACP, \\ Bruce K Rubin MEngr MD MBA FAARC, Alistair Stewart MSc, \\ and Catherine A Byrnes MBChB FRACP GCCE MD
}

\begin{abstract}
BACKGROUND: The upper airway humidifies and warms inspired gases before they reach the trachea, a process bypassed by the insertion of a tracheostomy, necessitating humidification of inspired gases. The optimal method of humidification is not known. METHODS: We conducted a short-term 20-hour study and a long-term 10-week randomized crossover study comparing a heated humidifier (HH) to a heat and moisture exchanger (HME) in children with established tracheostomies. Subjects were assessed for clinical events, clinical examination findings, airway cytokine levels, and airway secretion viscoelasticity. RESULTS: For the short-term study, 15 children were recruited; for the long-term study, 14 children were recruited. Children using the HH had decreased respiratory examination score $(P<.001)$ but no change in clinical events over the short term. There was a decrease in acute clinical events $(P=.008)$ in the long-term study. No differences were found in airway secretion viscoelasticity results or cytokine levels in either study, but these sample numbers were limited. CONCLUSIONS: Over 20 hours use, HH, compared to HME, improved work of breathing. Over a longer 10 week treatment period $\mathrm{HH}$ resulted in decreased adverse clinical events. Key words: child; tracheostomy; humidity; mucociliary clearance; rheology; inflammation; randomized controlled trial. [Respir Care 2014;59(1):46-53. (C) 2014 Daedalus Enterprises]
\end{abstract}

\section{Introduction}

The upper airway plays an important role in the physical defense of the lung by filtering, humidifying, and warming

Drs McNamara, Asher, and Byrnes are affiliated with the Department of Paediatrics, Child and Youth Health, University of Auckland, and with Starship Children's Hospital, Grafton, Auckland, New Zealand. Dr Rubin is affiliated with Children's Hospital of Richmond at Virginia Commonwealth University, and with the Department of Pediatrics, Virginia Commonwealth University, Richmond, Virginia. Mr Stewart is affiliated with the School of Population Health, University of Auckland, Auckland, New Zealand.

This study was partly supported by Fisher \& Paykel Healthcare, which manufactures the heated humidifier used in this study. Dr McNamara has disclosed relationships with Fisher \& Paykel Healthcare, GlaxoSmithKline, and Boehringer Ingelheim. Dr McNamara was partly supported by the New Zealand Foundation for Research Science and Technology, and a Joan Mary Reynolds fellowship. Dr Rubin has disclosed relationships with the United States National Institutes of Health, the Cystic Fibrosis Foundation, the Denny Hamlin Foundation, GlaxoSmithKline, Teleflex Medical, Reckitt Benckiser, Fisher \& Paykel Healthcare, Philips Respironics, Pharmaxis, Boehringer Ingelheim, and Bayer. Dr Byrnes has disclosed relationships with the Health Research Council of New Zealand inspired gases before they reach the trachea, preventing dehydration of airway secretions. The nose and oropharynx perform most of this conditioning. ${ }^{1,2}$ Insertion of a tracheostomy bypasses the upper airway, resulting in relatively cool and dry ambient room air entering the trachea directly. This may have adverse effects, causing cooling and drying of the mucosa, with slowing of mucociliary clearance and airway inflammation. ${ }^{3}$ The American Thoracic Society guidelines for care of a child with a chronic tracheostomy state that the "target for inspired gas temperature should be $32^{\circ}$ to $34^{\circ} \mathrm{C}$ and the target for inspired humidity should be 36 to $40 \mathrm{mg} \mathrm{H}_{2} \mathrm{O} / \mathrm{L}$." 3 Aerosol nebulizers, heated humidifiers (HHs), and heat and moisture

\footnotetext{
and Boehringer Ingelheim. The other authors have disclosed no conflicts of interest.

Correspondence: David G McNamara MBChB FRACP PhD, Department of Paediatrics, Starship Children's Hospital, Park Road Grafton, Auckland 1024 New Zealand. E-mail: davidmc@adhb.govt.nz.
}

DOI: $10.4187 /$ respcare. 02214 
exchangers (HMEs) are all used to condition inspired gases for children spontaneously breathing through tracheostomy tubes.

In our institution the standard is to provide an $\mathrm{HH}$ during sleep and an HME for time awake for children with longstanding tracheostomies. This practice developed after successful $\mathrm{HH}$ treatment was instituted for 2 children with tracheostomies and thick secretions, resulting in decreased admissions for pneumonia. ${ }^{4}$ Our hypothesis was that appropriate humidification of the airway would have positive effects in terms of secretions and clinical outcomes. For that purpose we conducted 2 studies over 2 periods of time: a short-term study and a long-term study. The aims of the first study were to compare the effectiveness of an HH compared to an HME when used over a 20-hour treatment period, as determined by emergency tracheostomy changes, the need for overnight suctioning, work of breathing, airway inflammation, and secretion viscoelasticity. The aims of the second study were to compare the effectiveness of an HH compared to an HME when used over a longer 10-week treatment period, as determined by the occurrence of major clinical events (hospital admission, lower-respiratory-tract infections, treatment failure), work of breathing, and airway inflammation.

\section{Methods}

The study was approved by the regional ethics committee and registered with the Australasian Clinical Trials Registry (short-term study ACTRN12605000263695, long-term study ACTRN12605000673640).

\section{Subjects}

After obtaining parental consent, children with a tracheostomy who were hospital in-patients or resident in a rehabilitation facility and who had safely undergone at least one tracheostomy tube change (for the short-term study) and were older than 6 months of age with a tracheostomy tube in place for at least 3 months (for the long-term study) were recruited. Exclusion criteria included subjects with cystic fibrosis, primary ciliary dyskinesia, primary immune deficiency, or under palliative care. For the long-term study, children were also excluded if the planned tracheostomy time, as determined by their primary otolaryngologist, was less than the study period of 20 weeks. Recruitment took place from November 2004 to August 2006.

\section{Study Design}

Randomization to one of 2 groups was performed using a computer generator table.

\section{QUICK LOOK}

\section{Current knowledge}

In tracheostomized children the optimal method of airway humidification (heated humidifier, aerosol therapy, or heat and moisture exchanger) is not known.

\section{What this paper contributes to our knowledge}

In children with long-term tracheostomy, heated humidification improved patient comfort and reduced the frequency of complications, compared to heat and moisture exchanger. The results of this small study require confirmation in an appropriately powered investigation.

Short-Term Study. Each treatment period was preceded by a night of $\mathrm{HH}$ treatment and then a 4 hour wash-out period with no treatment. Group A then underwent 20 hours of treatment with the $\mathrm{HH}$, followed by a recovery night (standard treatment with $\mathrm{HH}$ ), and then 20 hours of treatment with the HME. Group B underwent treatment in the reverse order. Assessments were performed at the start of treatment (end of wash-out), after 2 hours of treatment, and after 20 hours of treatment. Treatment allocation was unable to be concealed from families or the investigator for this study, but was concealed from persons performing laboratory analysis.

Long-Term Study. Group A underwent 10 weeks of treatment with the $\mathrm{HH}$ at night, HME during the day, followed by 10 weeks of treatment with the HME over the 24 hour period. Group B underwent treatment in the reverse order. The first 2 weeks of each period was considered a "wash-in" period, and clinical events were not counted unless the child was unable to tolerate treatment. Assessments were performed at recruitment and at the end of each treatment period. Treatment was concealed to those conducting clinical examination and laboratory measurements, but for practical reasons was not concealed from the primary investigator or the families of subjects.

\section{Study Interventions}

The HH used in this study (MR850, Fisher \& Paykel Healthcare, Auckland, New Zealand) was set to deliver air conditioned to $37^{\circ} \mathrm{C}$ and $100 \%$ relative humidity. The humidified system was made up of a CPAP flow source (HC211, Fisher \& Paykel Healthcare, Auckland, New Zealand) to generate the air flow, the MR850 HH, a humidifier chamber (HC300 or MR290, Fisher \& Paykel Healthcare, Auckland, New Zealand), a heated breathing circuit (HC505, Fisher \& Paykel Healthcare, Auckland, 


\section{Heated Humidification Improves Clinical Outcomes}

New Zealand), and a pediatric tracheostomy mask (Hudson/Teleflex Medical, Research Triangle Park, North Carolina) attached to the patient's tracheostomy. The mask is loosely applied over the tracheostomy so that no CPAP pressure is applied to the patient's airway. Air flow was adjusted to remove $\mathrm{CO}_{2}$ from the dead space of the circuit, and not to provide clinical benefit on work of breathing, according to the formula:

Flow (in $\mathrm{L} / \mathrm{min})=$ breathing frequency

$$
\times \text { weight (in } \mathrm{kg}) \times 3+5
$$

The HME (Thermovent-T, Portex/Smiths Medical, St Paul, Minnesota) houses filter paper that absorbs exhaled warmth and moisture and delivers it to the next inhaled breath. This is the HME device commonly used in our hospital and throughout New Zealand for children with tracheostomies. This device delivers humidification of $25 \mathrm{mg} \mathrm{H}_{2} \mathrm{O} / \mathrm{L}$ and $34^{\circ} \mathrm{C}$ at a tidal volume of $1,000 \mathrm{~mL}$, according to the manufacturer's specifications; however, performance is likely to be higher in children who have lower expiratory flows. Subjects received oxygen as prescribed by their treating physician, titrated prior to the study using continuous overnight oximetry recordings.

\section{Outcome Measures}

For the short-term study we monitored the occurrence of overnight clinical events: emergency tracheostomy tube changes, tracheostomy tube blockages, the need for suctioning, or the need for additional saline instillation to loosen secretions and assist suctioning. Tracheostomy tube blockage was defined as obstruction of the tracheostomy tube with secretions that did not clear with suctioning and required an emergency tube change. All airway cares were undertaken according to our usual clinical guidelines and were recorded.

For the long-term study, major adverse clinical events included episodes of acute lower-respiratory-tract infection, acute hospital admission for any cause, acute hospital admission for a respiratory cause, tracheostomy tube occlusion, emergency tracheostomy tube changes, and withdrawal from the study or "treatment failure." Lowerrespiratory-tract infection was defined as an increase in respiratory effort and airway secretions associated with new changes on chest $\mathrm{x}$-ray or on auscultation and where either oral or intravenous antibiotics were prescribed. Treatment failure, or inability to tolerate one treatment, occurred when airway secretions were persistently thick, requiring hourly suction for a period of $\geq 3$ days, or the parent/caregiver and/or the primary medical team or investigator believed it was unsafe to continue. Parents of subjects were asked to contact the primary investigator if any of these events occurred, and were also contacted by telephone on a fortnightly basis during the study, to collect clinical event data.

A respiratory clinical score developed for children with asthma and bronchiolitis was used for both studies. ${ }^{5}$ This is a 4-point (0-3) scoring system of increasing severity for:

1. Breathing frequency measured over one minute, compared to normal for age

2. Retractions

3. Wheeze

4. Dyspnea (judged according to feeding, activity and level of consciousness)

5. Crackles on auscultation of the chest. ${ }^{5}$

Oxygen saturation $\left(\mathrm{S}_{\mathrm{pO}_{2}}\right)$ was measured by a pulse oximeter (Radical, Masimo, Irvine, California) during a 2minute period of quiet breathing. For the short-term study, overnight oximetry saturations and pulse rate were continuously recorded for a 12-hour period, and the mean data were analyzed with oximetry software (Profox, Profox Associates, Escondido, California), excluding periods of artifact. $\mathrm{S}_{\mathrm{pO}_{2}}$ was not analyzed for children on oxygen, as the $\mathrm{F}_{\mathrm{IO}_{2}}$ could not be precisely replicated between the 2 treatments.

For both studies, suctioning of airway secretions from the tracheostomy was standardized. The HME was removed and the external lumen of the tracheostomy tube wiped clean with sterile gauze. A size $8 \mathrm{~g}$ French suction catheter with thumb trap (Triflo, Allegiance Healthcare, Jackson, Mississippi) was inserted to a predetermined depth of $1 \mathrm{~cm}$ beyond the terminal end of the tube. Suction of $100 \mathrm{~mm} \mathrm{Hg}$ was applied and the suction catheter slowly withdrawn with gentle swirling until at the tracheostomy stoma opening, and then repeated once. The sample of airway secretions acquired in the thumb trap was visually inspected, and a visual secretion assessment score on a 3-point scale applied for difficulty of catheter insertion, the color of the secretions, the volume of the secretions, and the thickness of the secretions after $1 \mathrm{~mL}$ of normal saline had been suctioned through the catheter.6,7

Inflammatory cytokines were measured for both studies. Secretions obtained by suctioning were transferred to a pre-weighed $0.5 \mathrm{~mL}$ centrifuge tube (Nunc, Thermo Fisher Scientific, Waltham, Massachusetts) with O-ring, and stored at $-80^{\circ} \mathrm{C}$. Samples were thawed on ice for analysis and resuspended in sterile phosphate-buffered solution at a final concentration of $100 \mathrm{mg}$ sputum $/ \mathrm{mL}$ phosphatebuffered solution. The samples were then ultracentrifuged at $90,000 \times \mathrm{g}$ for 1.5 hours at $4^{\circ} \mathrm{C}$ (L70 Ultracentrifuge, Beckman Coulter, Brea, California), using a type $50.4 \mathrm{Ti}$ ultracentrifuge rotor. Supernatants were aliquoted in sterile $1.5 \mathrm{~mL}$ tubes (Eppendorf International, Hamburg, 


\section{Heated Humidification Improves Clinical Outcomes}

Germany) (at least 4 aliquots). Samples were then stored at $-80^{\circ} \mathrm{C}$ until required for enzyme-linked immunosorbent assay (ELISA) analysis. Inflammatory cytokines were analyzed using ELISA and according to the manufacturer's instructions. Interleukin-8 (IL-8) was analyzed using a human IL-8 ELISA kit (PeproTech Worldwide, Rocky Hill, New Jersey), IL-1beta (IL-1 $\beta$ ) using an IL- $1 \beta$ ELISA kit (OptEIA, BD Biosciences, San Jose, California), and tumor necrosis factor-alpha using a human tumor necrosis factor alpha ELISA development kit (PeproTech Worldwide, Rocky Hill, New Jersey).

For the short-term study the viscoelastic properties of airway secretions were measured using a cone and plate rheometer with specially instrumented shallow cone (AR1000, TA Instruments, New Castle, Delaware). We did not attempt to extract and separately analyze the mucus component from the airway secretions. Elastic modulus (storage modulus, $\mathrm{G}^{\prime}$ ) and viscous modulus (loss modulus, G") were determined by measuring stress strain curves of thawed $20 \mu \mathrm{L}$ samples at driving frequencies of $0.01-10,000 \mathrm{rad} / \mathrm{s}$. The $\mathrm{G}^{\prime}$ and the $\mathrm{G}^{\prime \prime}$ of the specimens were determined from these curves over the linear portion between 1 and $100 \mathrm{rad} / \mathrm{s}$, using nondestructive creep transformation. ${ }^{8}$ Due to difficulties obtaining adequate volume samples, with cytokine measurement taking priority, only 10 samples on treatment were available for rheology measurement, with the 2 and 20 hour results pooled for analysis.

\section{Statistical Analyses}

Paired comparisons allowing for period effects and fixed subject effects were conducted using generalized linear models and within-subject contrasts, using statistics software (SAS 9.1, SAS Institute, Cary, North Carolina), as recommended for analysis of crossover studies. ${ }^{9}$ For the 20-hour study a model was used that incorporated both the 2 and 20 hour time periods, so only a single $P$ value is presented. For non-normally distributed data, log or square root transformations were performed.

The outcomes for the short-term and the long-term studies were the occurrence of clinical events as presented here. As recorded in the trial registry, when planning the study we included radio-aerosol mucociliary clearance scans as a primary outcome, but we were unable to obtain repeatable results in children initially completing the study, due to variable radio-aerosol deposition with inconsistent breathing patterns between scans, and movement artifact between images. We therefore abandoned this as an outcome. For the long-term study a power calculation assuming a 50\% reduction in major clinical events over an 8-week period from $90 \%$ of the study population to $45 \%$, showed that a sample size of 13 subjects would be required to give a power of $80 \%$ at a significance level of .05 . For the short-term study the sample size calculation was based on assuming a difference for mucus viscoelastic modulus between the means of 0.3 and a standard deviation of the difference of 0.5 indicated that a sample size of 15 would give a power of $80 \%$ and significance of .05 .

\section{Results}

For the short-term study 15 children were enrolled: 8 male, mean age 4 years 6 months (range 1 month to 17 years), and mean duration of tracheostomy 1 year 3 months (range 5 months to 16 years 9 months). Craniofacial abnormalities, including Pierre Robin sequence $(n=4)$ and neurologic causes $(n=4)$, were the most common indications for tracheostomy. Two thirds of the children had comorbidities, with neurological conditions being the most common. All children completed the study with no protocol violations.

No episodes of tracheostomy occlusion occurred during either treatment period. There was one unscheduled tracheostomy tube change for oxygen desaturation, which occurred during treatment with $\mathrm{HH}$. Five of the children were on oxygen for all or part of the study, and were not assessed for $\mathrm{S}_{\mathrm{pO}_{2}}$. No significant differences were found between $\mathrm{HH}$ and $\mathrm{HME}$ for the overnight suctioning frequency $(6.8 \pm 5.0$ vs $7.7 \pm 5.0, P=.33)$, or number requiring normal saline instillation $(1.40 \pm 2.16$ vs $1.07 \pm 1.39, P=.42$ ). There was also no difference in mean overnight $\mathrm{S}_{\mathrm{pO}_{2}}(97.4 \% \pm 1.3$ vs $97.7 \% \pm 1.3$, $P=.46)$ or mean pulse rate $(115.7 \pm 26.9$ beats $/ \mathrm{min}$ vs $112.3 \pm 31.8$ beats $/ \mathrm{min}, P=.45$ ).

The breathing frequency was lower $(P=.04)$ on $\mathrm{HH}$, compared to HME after 2 hours $(38.5 \pm 18.8$ breaths $/ \mathrm{min}$ vs $44.1 \pm 17.4$ breaths/min) and after 20 hours ( $40.5 \pm 16.7$ breaths/min vs $42.5 \pm 18.6$ breaths $/ \mathrm{min})$ (Table 1). $\mathrm{S}_{\mathrm{pO}_{2}}$ in children breathing room air was similar on $\mathrm{HH}$ and $\mathrm{HME}(P=.06)$. The total respiratory examination score was lower during $\mathrm{HH}$ than during $\mathrm{HME}$ $(P<.001)$ after 2 hours $(2.4 \pm 2.2$ vs $3.6 \pm 2.4)$ and after 20 hours $(2.5 \pm 2.0$ vs $3.7 \pm 2.6)$. There were also significant differences in the components of the total score severity of retractions $(P=.01)$ and severity of wheeze $(P=.02)$.

For the long-term study a total of 36 children were identified during the study period (Fig. 1). Four were considered ineligible due to dependence on home ventilation, and 4 due to inability to gain informed consent. Two families were not approached, due to parental distress. Of the remaining 26 families approached, 12 declined consent. Fourteen children were therefore enrolled: 8 male, mean age 2 years 10 months (range 5 months to 15 years 3 months), and mean duration of tracheostomy 2 years 4 months years (range 2 months to 15 years). Craniofacial syndromes, including Pierre-Robin sequence, were the 


\section{Heated Humidification Improves Clinical Outcomes}

Table 1. Clinical Examination Results for Short-Term Study

\begin{tabular}{|c|c|c|c|c|c|c|c|c|}
\hline & \multicolumn{2}{|c|}{ Baseline } & \multicolumn{2}{|c|}{2 Hours } & \multicolumn{2}{|c|}{20 Hours } & \multicolumn{2}{|c|}{$P$} \\
\hline & MR850 & Thermovent- $\mathrm{T}$ & MR850 & Thermovent- $\mathrm{T}$ & MR850 & Thermovent- $\mathrm{T}$ & $\begin{array}{l}\text { Overall } \\
\text { Study } \\
\text { Period } \\
\text { Effect }\end{array}$ & $\begin{array}{c}\text { Overall } \\
\text { Study } \\
\text { Treatment } \\
\text { Effect }\end{array}$ \\
\hline Pulse rate, beats/min & $134.1 \pm 28.1$ & $125.7 \pm 28.1$ & $128.2 \pm 24.7$ & $125.3 \pm 26.8$ & $125.5 \pm 25.3$ & $128.0 \pm 25.6$ & .08 & .97 \\
\hline $\begin{array}{l}\text { Breathing frequency, } \\
\text { breaths/min }\end{array}$ & $39.3 \pm 20.9$ & $38.1 \pm 20.8$ & $38.5 \pm 18.8$ & $44.1 \pm 17.4$ & $40.5 \pm 16.7$ & $42.5 \pm 18.6$ & .9 & .04 \\
\hline Oxygen saturation, $\%$ & $97.7 \pm 2.1$ & $97.3 \pm 2.8$ & $98.3 \% \pm 1.7$ & $97.9 \pm 1.6$ & $98.4 \pm 1.7$ & $97.4 \pm 2.4$ & .13 & .06 \\
\hline $\begin{array}{l}\text { Total respiratory } \\
\text { examination score }\end{array}$ & $2.9 \pm 2.1$ & $3.4 \pm 2.2$ & $2.4 \pm 2.2$ & $3.6 \pm 2.4$ & $2.5 \pm 2.0$ & $3.7 \pm 2.6$ & .38 & $<.001$ \\
\hline Total secretion score & $6.9 \pm 1.5$ & $6.5 \pm 1.0$ & $6.5 \pm 1.2$ & $6.5 \pm 1.1$ & $6.5 \pm 1.4$ & $7.4 \pm 1.3$ & .31 & .09 \\
\hline
\end{tabular}

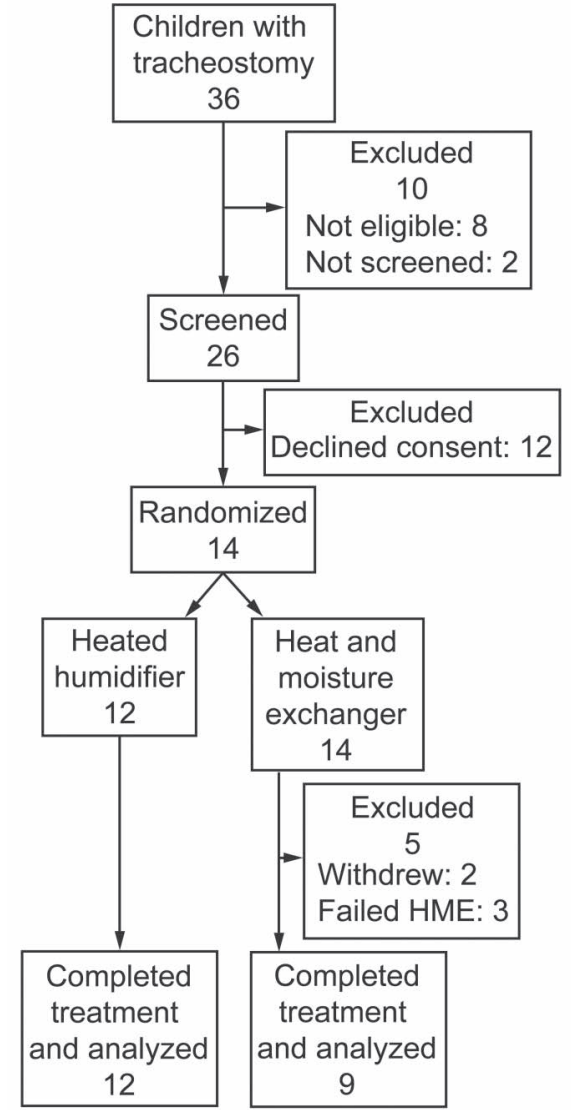

Fig. 1. Flow chart for the long-term study. HME = heat and moisture exchanger.

most common indication for tracheostomy, and 9 of the children had comorbidities. None were reportedly exposed to environmental tobacco smoke. Two children withdrew during the first period, while on HME. One family declined the randomization order and had treatment order reassigned to $\mathrm{HH}$, then $\mathrm{HME}$, and one child underwent the
2 treatment periods separated by 12 months but were included in the analysis.

Fewer subjects had an adverse clinical event during $\mathrm{HH}$ than during HME (5 vs 11, $P=.008$ ) (Fig. 2). The events included lower-respiratory-tract infections (4 vs 8 ), acute respiratory admissions (2 vs 5), and tracheostomy tube occlusions/emergency changes ( 2 vs 5 ). There were also fewer treatment failures and/or study withdrawal during HH (0 vs 3 ). However, there were no differences in breathing frequency, oxygenation, or work of breathing as measured by the clinical examination score. Children receiving HH during sleep used fewer HMEs per day $(3.3 \pm 1.9$ vs $4.0 \pm 1.7, P=.02$ ).

Adherence data for the $\mathrm{HH}$ period was downloaded for 9 subjects, and showed that the machine was switched on for a mean \pm SD $94.8 \pm 9.2 \%$ of days, and $11.8 \pm 2.8$ hours per day. More parents reported satisfaction with $\mathrm{HH}$ than with HME (11 vs 9 satisfied, 0 vs 2 not satisfied, $P=.02$ ), with no statistical difference in final preference ( 8 vs 2 , $P=.07)$. There were no differences in visual secretion assessment in either study (see Table 1).

No significant treatment effects were found for any of the inflammatory cytokines measured. In the short-term study the $P$ values were $.73, .59$, and .49 for IL- 8 , IL1 $\beta$, and tumor necrosis factor alpha, respectively, and the corresponding values for the long-term study were $.21, .54$, and .66. There were no significant differences in the rheology measurements between treatments in the short-term study $(P=.69$ for the viscous modulus at 1 and $100 \mathrm{rad} / \mathrm{s}$, $P=.55$ and 0.84 for the elastic modulus). Only 10 samples of adequate quality were available for this analysis.

\section{Discussion}

Children using $\mathrm{HH}$ over 20 hours of treatment had lower (better) respiratory examination scores but no differences in adverse clinical events, compared to using HME. Over 


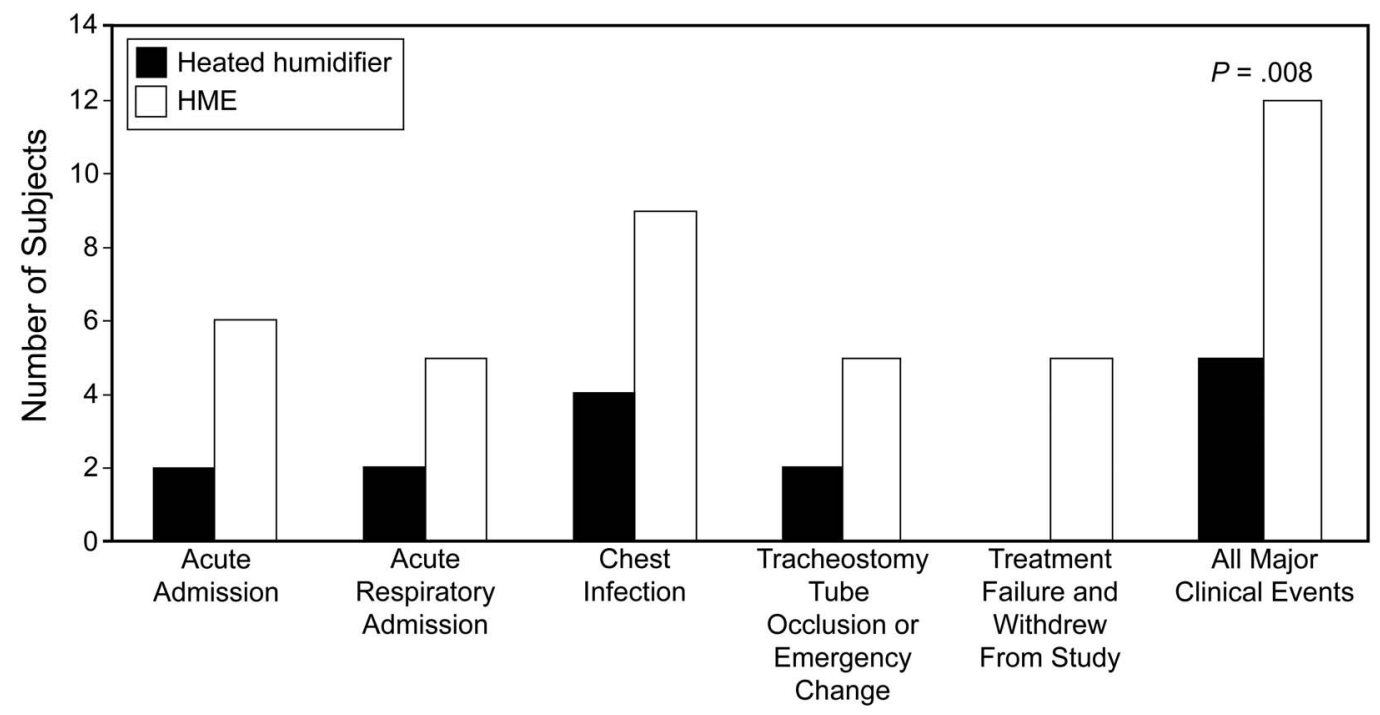

Fig. 2. Numbers of subjects with major clinical events during overnight treatment with heated humidifier or heat and moisture exchanger (HME).

Table 2. Performance and Cost of Thermovent-T Heat and Moisture Exchanger Versus MR850 Humidifier

\begin{tabular}{|c|c|c|c|c|c|}
\hline & \multirow{2}{*}{ Performance* } & \multirow{2}{*}{$\begin{array}{c}\text { Dead } \\
\text { Space* } \\
(\mathrm{mL})\end{array}$} & \multirow{2}{*}{$\begin{array}{l}\text { Resistance* } \\
\left(\mathrm{cm} \mathrm{H} \mathrm{H}_{2} \mathrm{O} / \mathrm{L} / \mathrm{s}\right)\end{array}$} & \multicolumn{2}{|c|}{$\begin{array}{c}\text { Cost } \\
\text { New Zealand Dollars }\end{array}$} \\
\hline & & & & Unit & Annual \\
\hline Thermovent- $\mathrm{T}$ & $25 \mathrm{mg} \mathrm{H} \mathrm{H}_{2} \mathrm{O} / \mathrm{L}$ and $34^{\circ} \mathrm{C}$ & 7 & 2 & 4 & 5,840 \\
\hline MR850 & $44 \mathrm{mg} \mathrm{H} \mathrm{H}_{2} \mathrm{O} / \mathrm{L}$ and $37^{\circ} \mathrm{C}$ & 0 & 0 & 1,395 & $1,753 \dagger$ \\
\hline
\end{tabular}

* According to manufacturer.

$\dagger$ MR850 cost includes supplying sterile water; electricity cost not included. Cost of Thermovent-T when awake not included (4,818 New Zealand dollars).

10-week treatment periods, fewer children with long-term tracheostomy had an adverse clinical event with HH than with $\mathrm{HME}$; there were no treatment failures with $\mathrm{HH}$, but 2 subjects withdrew from the study while on HME. The effects of inadequate humidification are known to increase with duration, ${ }^{10}$ which may explain the differences in clinical events between the 20-hour and 10-week studies.

It has been reported that in adults mechanically ventilated in the ICU there are fewer endotracheal tube occlusions with HH than with HME, ${ }^{11-15}$ despite the fact that subjects with "thick" airway secretions were excluded from all trials. ${ }^{16}$ In tracheostomized adult patients there has been one published long-term study of humidification, which compared HME to no treatment and found a decrease in the occurrence of pneumonia. ${ }^{17}$ A more recent study in laryngectomized adult patients found better cough and adherence to HME than to HH in the immediate postoperative period. ${ }^{18}$ The humidifier in that study did not use heated tubing, which may have resulted in condensate, potentially affecting outcomes. In the long-term study we also documented significantly fewer lower-respiratory-tract infections, acute respiratory admissions, tracheostomy tube occlusions/emergency changes, and treatment failures during the $\mathrm{HH}$ period. This is important clinically and also to the parents and children, not only because of potential adverse effects of the single events, but also improving parental confidence, rather than their feeling the need to constantly monitor the child. The decreased use of almost 1 additional HME per day when on $\mathrm{HH}$ overnight also represents a significant cost saving, equivalent to $\$ 360$ (United States dollars) per month (Table 2 shows the total annual costs).

During the short-term study we found a difference in clinical examination findings between $\mathrm{HH}$ and $\mathrm{HME}$, but the investigator was not masked to treatment group. During the long-term study, no difference between treatments was found during blinded clinical examination: this lack of difference may have been due to all subjects wearing the HME at the time of assessment.

The increased breathing frequency and respiratory examination score found at 20 hours in the HME group may have been a direct mechanical effect, with increased dead space and increased airway resistance. The HME had a dead space of $7 \mathrm{~mL}$ and resistance of $2 \mathrm{~cm} \mathrm{H}_{2} \mathrm{O} / \mathrm{L} / \mathrm{s}$. In 


\section{Heated Humidification Improves Clinical Outcomes}

ambulatory adults spontaneously breathing through tracheostomy, an HME did not decrease respiratory function, ${ }^{19}$ but in adults ventilated for respiratory failure an HME decreased ventilation, with a compensatory increase in work of breathing. ${ }^{20-25}$ This dead space increase is relatively greater in an infant or small child than in an adult. We recruited children ages 1 month to 16 years. The youngest child in this study was $3.41 \mathrm{~kg}$ at enrollment and would have had a tidal volume of approximately $10 \mathrm{~mL}$ (3-5 mL/kg). The oldest child was 17 years of age, with a weight of $56.5 \mathrm{~kg}$ and approximate tidal volume of $280 \mathrm{~mL}$. While the increased work of breathing may not be clinically important, it can increase the energy and caloric requirements for respiration.

We found no difference in the visual assessment of suctioned airway secretions in either study. A study of adults ventilated in an ICU found that all the subjects had thin secretions while on $\mathrm{HH}$, and moderate or thick secretions after several days treatment with HME. ${ }^{7}$ The lack of difference in our study may be due to the smaller volume of secretions, the smaller size of the suction catheter used, shear forces of $100 \mathrm{~mm} \mathrm{Hg}$ suction, or smaller volumes of fluid suctioned through the catheter.

While the clinical differences between HH and HME may be due to or associated with changes in secretion rheology or inflammation, we could not demonstrate this in our studies. The cytokines were collected at the tracheostomy site and therefore may have been produced hours before in the lower respiratory tract. Cytokine response to an insult may take hours and involves interactions between inflammatory triggers, resident inflammatory cells, and migration of inflammatory cells to the site of initial injury, similar to the late response in asthma. ${ }^{26}$ Our viscoelasticity results are lower than previous studies, which have analyzed mucus from airway samples or sputum. Our samples included the entire airway secretion sample, not the mucus component alone, including an amount of periciliary liquid layer and condensate.

We also performed a parallel qualitative study, interviewing the parents of 10 children. ${ }^{27} \mathrm{We}$ found that in managing their child's care, parents of children with tracheostomies balanced the difficulties of using a treatment against its benefits to the child's health, decreased parental worry, and decreased need for the parent to wake in the night. Most of the interviewed parents elected to continue using the $\mathrm{HH}$, but a few elected to use HME when the difficulties of $\mathrm{HH}$ outweighed the benefits.

The small sample size is a limitation in both studies, most marked in the number of secretion samples available for analysis. The research planned was based on tracheostomy insertion numbers in preceding years. However, with improved noninvasive ventilation there were fewer patients, and those who had tracheostomies were decannulated much more quickly. As well, many of these chil- dren were placed in care, making it unsuitable for them to be enrolled in the study.

\section{Conclusions}

In children with tracheostomy, overnight $\mathrm{HH}$ for 10 weeks reduced the number of acute clinical events and was associated with fewer study withdrawals and better parental satisfaction. Over a 20-hour period the HME caused higher respiratory effort than the $\mathrm{HH}$. We recommend $\mathrm{HH}$ use for children with thick secretions, repeated chest infections, or recurrent hospital admission for respiratory illness. A multicenter study would be helpful to investigate the most appropriate method of humidification for children with tracheostomy.

\section{ACKNOWLEDGMENTS}

We are grateful to the Children's Research Centre, Auckland, New Zealand, which is funded by the Starship Foundation, for the use of their facilities; to Cathy Douglas, Sheri Biscaldi, and Shelley Broome, for establishing children on the heated humidification devices; to Mirjana Jaksic MD, for assisting with the recruitment and data collection; and to Melissa A Yopp, Virginia Commonwealth University, for technical expertise.

\section{REFERENCES}

1. Primiano FP Jr, Montague FW Jr, Saidel GM. Measurement system for respiratory water vapor and temperature dynamics. J Appl Physiol Respir Environ Exerc Physiol 1984;56(6):1679-1685.

2. Irlbeck D. Normal mechanisms of heat and moisture exchange in the respiratory tract. Respir Care Clin N Am 1998;4(2):189-198.

3. Sherman JM, Davis S, Albamonte-Petrick S, Chatburn RL, Fitton C, Green $\mathrm{C}$, et al. Care of the child with a chronic tracheostomy. This official statement of the American Thoracic Society was adopted by the ATS Board of Directors, July 1999. Am J Respir Crit Care Med 2000;161(1):297-308.

4. Edwards EA, Byrnes CA. Humidification difficulties in two tracheostomized children. Anaesth Intensive Care 1999;27(6):656-658.

5. Liu LL, Gallaher MM, Davis RL, Rutter CM, Lewis TC, Marcuse EK. Use of a respiratory clinical score among different providers. Pediatr Pulmonol 2004;37(3):243-248.

6. Suzukawa M, Usada Y, Numata K. The effects on sputum characteristics of combining an unheated humidifier with a heat-moisture exchanging filter. Respir Care 1989;34(10):976-984.

7. Branson RD, Davis K Jr, Campbell RS, Johnson DJ, Porembka DT. Humidification in the intensive care unit. Prospective study of a new protocol utilizing heated humidification and a hygroscopic condenser humidifier. Chest 1993;104(6):1800-1805.

8. King M, Rubin BK. Mucus rheology: relationship with transport. In: Takishima T, editor. Airway secretion: physiological bases for the control of mucus hypersecretion. New York: Marcel Dekker; 1994: 283-314.

9. Senn S. Cross-over trials in clinical research. Chichester: John Wiley \& Sons; 2002.

10. Williams R, Rankin N, Smith T, Galler D, Seakins P. Relationship between the humidity and temperature of inspired gas and the function of the airway mucosa. Crit Care Med 1996;24(11):1920-1929. 


\section{Heated Humidification Improves Clinical Outcomes}

11. Cohen IL, Weinberg PF, Fein IA, Rowinski GS. Endotracheal tube occlusion associated with the use of heat and moisture exchangers in the intensive care unit. Crit Care Med 1988;16(3):277-279.

12. Martin C, Perrin G, Gevaudan MJ, Saux P, Gouin F. Heat and moisture exchangers and vaporizing humidifiers in the intensive care unit. Chest 1990;97(1):144-149.

13. Kollef MH, Shapiro SD, Boyd V, Silver P, Von Harz B, Trovillion $\mathrm{E}$, et al. A randomized clinical trial comparing an extended-use hygroscopic condenser humidifier with heated-water humidification in mechanically ventilated patients. Chest 1998;113(3):759-767.

14. Roustan JP, Kienlen J, Aubas P, Aubas S, du Cailar J. Comparison of hydrophobic heat and moisture exchangers with heated humidifier during prolonged mechanical ventilation. Intensive Care Med 1992; 18(2):97-100.

15. Doyle A, Joshi M, Frank P, Craven T, Moondi P, Young P. A change in humidification system can eliminate endotracheal tube occlusion. J Crit Care 2011;26(6):637; e1-e4.

16. Kola A, Eckmanns T, Gastmeier P. Efficacy of heat and moisture exchangers in preventing ventilator-associated pneumonia: metaanalysis of randomized controlled trials. Intensive Care Med 2005; 31(1):5-11.

17. Jones AS, Young PE, Hanafi ZB, Makura ZG, Fenton JE, Hughes JP. A study of the effect of a resistive heat moisture exchanger (Trachinaze) on pulmonary function and blood gas tensions in patients who have undergone a laryngectomy: a randomized control trial of 50 patients studied over a 6-month period. Head Neck 2003; 25(5):361-367.

18. Merol JC, Charpiot A, Langagne T, Hemar P, Ackerstaff AH, Hilgers FJ. Randomized controlled trial on postoperative pulmonary humidification after total laryngectomy: external humidifier versus heat and moisture exchanger. Laryngoscope;122(2):275-281.

19. Vitacca M, Clini E, Porta R, Ambrosino N. Breathing pattern and respiratory mechanics in chronically tracheostomized patients with chronic obstructive pulmonary disease breathing spontaneously through a hygroscopic condenser humidifier. Respiration 1997;64(4) 263-267.

20. Le Bourdelles G, Mier L, Fiquet B, Djedaini K, Saumon G, Coste F, et al. Comparison of the effects of heat and moisture exchangers and heated humidifiers on ventilation and gas exchange during weaning trials from mechanical ventilation. Chest 1996;110(5):1294-1298.

21. Johnson PA, Raper RF, Fisher MM. The impact of heat and moisture exchanging humidifiers on work of breathing. Anaesth Intensive Care 1995;23(6):697-701.

22. Iotti G, Olivei M, Palo A, Galbusera C, Veronesi R, Comelli A, et al. Unfavorable mechanical effects of heat and moisture exchangers in ventilated patients. Intensive Care Med 1997;23(4):399-405.

23. Romano E, Gullo A, Vacri A, Bonifacio R, Caristi D. Effects of a heat and moisture exchanger on carbon dioxide equilibrium during mechanical ventilation with the Bain circuit. Eur J Anaesthesiol 1987;4(3):183-186.

24. Jaber S, Chanques G, Matecki S, Ramonatxo M, Souche B, Perrigault $\mathrm{PF}$, et al. Comparison of the effects of heat and moisture exchangers and heated humidifiers on ventilation and gas exchange during non-invasive ventilation. Intensive Care Med 2002;28(11): 1590-1594.

25. Pelosi P, Solca M, Ravagnan I, Tubiolo D, Ferrario L, Gattinoni L. Effects of heat and moisture exchangers on minute ventilation, ventilatory drive, and work of breathing during pressure-support ventilation in acute respiratory failure. Crit Care Med 1996;24(7): 1184-1188.

26. Busse WW, Lemanske RF Jr. Asthma. N Engl J Med 2001;344(5): 350-362.

27. McNamara DG, Dickinson AR, Byrnes CA. The perceptions and preferences of parents of children with tracheostomies in a study of humidification therapy. J Child Health Care 2009;13(3):179-197.

This article is approved for Continuing Respiratory Care Education credit. For information and to obtain your CRCE

(free to AARC members) visit

www.rcjournal.com

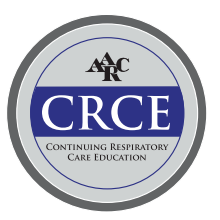

